\title{
Money Ethic mempengaruhi Penggelapan Pajak: Peran Love of Money
}

\author{
Agung Dwi Nugroho ${ }^{\mathrm{a}, 1, *}$, Faishal Prahatma Ganinda ${ }^{\mathrm{b}, 2}$, Kahfi Fikrianoor ${ }^{\mathrm{c}, 3}$, Amir Hidayatulloh ${ }^{\mathrm{d}, 4}$ \\ 1,2,3 Universitas Ahmad Dahlan, Yogyakarta, Indonesia \\ email: ${ }^{2}$ agungdwinugroho846@gmail.com,2 prahatmag@gmail.com,3 kahfifikri@gmail.com, 4 amir.hidayatulloh@act.uad.ac.id \\ * corresponding author
}

\section{ARTICLE INFO}

Article history

Received 2020-05-20

Revised 2020-12-22

Accepted 2020-12-30

Keywords

Money Ethic, Tax Evasion, Love of Money

\begin{abstract}
The purpose of this research was to determine the role of love of money on the effect of money ethics on personal taxpayer compliance. The population in this research is individual taxpayers in the Special Region of Yogyakarta. The sample in this research is an individual taxpayer in Gunungkidul district. Sampling in this research uses purposive sampling, with the criteria (1) individual taxpayers who have a NPWP, (2) personal taxpayers who carry out business activities or free work. Data collection in the research used a questionnaire distributed directly to respondents who met the criteria. Respondents in this research were 42 respondents. Data analysis techniques in this research used Partial Least Square with the help of WarpPLS. This research found that tax evasion was influencea by money ethics and love of money. This research also proves that love of money moderates the influence between money ethics and tax evasion.
\end{abstract}

\section{PENDAHULUAN}

Pajak menurut Wankhar \& Diana (2018), didefinisikan sebagai pungutan oleh negara yang tidak memberikan balas jasa secara langsung, sifatnya mengikat dan dapat dipaksakan, yang digunakan untuk kemakmuran rakyatnya sendiri. Pajak sangat berperan dan memiliki kontribusi yang cukup besar dalam penerimaan negara non migas, seperti Indoensia (Rosianti \& Mangoting, 2014).

Penerimaan dari pajak digunakan oleh pemerintah untuk membangun jalan, serta memperbaiki fasilitas. Hal ini dilakukan guna meningkatkan kesejahteraan dan menunjang ekonomi rakyat agar menjadi lebih baik. Akan tetapi, kegiatan ini perlu didukung oleh pendanaan yang besar (Siamena, Sabijono, \& Warongan, 2017). Pendanaan yang besar tersebut disebabkan oleh perkembangan teknologi dan kebutuhan negara. Pemerintah berupaya untuk mengurangi ketergantungan pada sumber dana eksternal yang dapat dilakukan dengan peningkatan sumber pembiayaan pembangunan internal, salah satunya melalui pajak (Siamena et al., 2017).

Menurut Basri, \& Silaen (2015), peningkatan pajak salah satunya dilihat dari tingkat kepatuhan pajak yang dilakukan oleh wajib pajak. Kepatuhan wajib pajak dalam hal ini diartikan sebagai wajib pajak yang mengerti atas kebijakan, kewajiban dan hak yang harus dilaksanakannya. Adapun wewenang yang diberikan kepada fiskus, berdasarkan undang-undang yang sifatnya memaksa wajib pajak supaya mematuhi kebijakan perpajakan.

Penerimaan pajak hingga akhir November 2019 mencapai Rp1.136,17 triliun. Penerimaan pajak baru tercapai 72,02 persen dari target Anggaran Pendapatan Belanja Negara (APBN) 2019. Hal ini menyebabkan penurunan 0,04 persen dari tahun 2018 sebesar Rp1.136,66 triliun. Salah satu penyebabnya adalah penerimaan penerimaan Pajak Penghasilan (PPh) Migas tercatat hanya Rp52,9 triliun dari target Rp66,2 triliun (Putra, 2019).

Penurunan pajak menurut Suminarsasi (2011), mengindikasikan bahwa terjadi praktek pengelakan/kecurangan pajak (Tax Evasion) yang dilakukan oleh wajib pajak. Hal ini menyebabkan pengaruh penurunan pajak diakibatkan oleh adanya tax evasion. Tax evasion diartikan sebagai penghindaran pajak yang dilakukan oleh wajib pajak karena pajak yang terlalu tinggi dan dilakukan secara ilegal. Pengelakan pajak ini seperti pembuatan laporan keuangan dan faktur palsu yang tidak sesuai dengan laporan keuangan yang sesungguhnya. Sehingga pemasukan negara pun akan berpengaruh atau akan turun (Rosianti \& Mangoting, 2014). 
Faktor lain yang dapat menyebabkan penuruna penerimaan pemerintah dari sektor pajak adalah Money Ethic. Hal ini diperkuat oleh hasil penelitian Tang (2002) yang menyatakan bahwa money ethic berpengaruh terhadap kepatuhan wajib pajak. Hal ini karena ketika individu cinta akan uang maka individu tersebut akan menyimpan uangnya tidak untuk dibelanjakan atau digunakan sebagai pembayaran pajak. Hal ini menjadikan uang menjadi aspek yang sangat penting dalam kehidupan seharihari, seperti halnya di Amerika, kesuksesan dapat diukur dengan banyaknya pendapatan yang dihasilkan (Rosianti \& Mangoting, 2014). Oleh karena itu, love of money memiliki peran saat pengambilan keputusan yang dilakukan individu. Dari uraian sebelumnya, maka tujuan penelitian ini adalah untuk mengetahui peran love of money pada pengaruh money ethic terhadap kepatuhan wajib pajak orang pribadi.

Menurut Rosianti \& Mangoting (2014), penghindaran pajak dilakukan oleh wajib pajak secara illegal dengan melanggar undang-undang. Kecurangan pajak timbul karena adanya sikap money ethic money ethic yang terdapat dalam setiap persepsian individu ketika akan membayar pajak dan timbul pertimbangan. Sehingga, hal ini akan memunculkan pengaruh negatif yaitu terjadinya penggelapan pajak. Menurut Mitchell \& Mickel (1999), menyatakan bahwa kepribadian individu merupakan variabel sikap yang dapat memengaruhi hubungan dengan uang (money ethic), bahkan uang dianggap sebagai segala sumber kejahatan. Hasil penelitian Lau, Choe \& Tan, (2013), menyatakan bahwa semakin tinggi etika uang yang dimiliki oleh individu maka akan semakin besar individu tersebut akan memperlakukan uang secara tidak etis seperti penggelapan pajak. Berdasarkan uraian diatas maka hipotesis pertama $\left(\mathrm{H}_{1}\right)$ dalam penelitian ini adalah sebagai berikut:

\section{$\mathrm{H}_{1}$ : Money ethic berpengaruh terhadap tax evasion}

Menurut Basri (2014), Love of Money memiliki hubungan yang negatif mengenai penggelapan pajak. Hal ini timbul karena tingkat love of money yang semakin tinggi yang dimiliki individu maka kecenderungan penggunaan uang yang positif akan menurun dan begitu pula sebaliknya. Hal ini juga didukung oleh penelitian Lau, Choe, \& Tan, (2013), kecintaan seseorang terhadap uang akan melibatkan seseorang melakukan tindakan yang tidak sesuai dan akan dengan mudah melakukan penggelapan pajak. Hal ini disebabkan orang yang memiliki kecintaan yang lebih tinggi dan menjadikan uang sebagai prioritas, sehingga dalam memenuhi kebutuhannya individu tersebut akan melakukan segala cara dengan hal yang tidak etis. Berdasarkan uraian diatas maka hipotesis Kedua $\left(\mathrm{H}_{2}\right)$ dalam penelitian ini adalah sebagai berikut:

\section{$\mathrm{H}_{2}$ : Love of money berpengaruh terhadap tax evasion}

Kecintaannya terhadap uang akan memengaruhi suatu etika, sehingga akan timbul tindakan yang tidak etis yang akan mendorong terjadinya tindakan penggelapan pajak (Basri, 2014). Menurut Lau, Choe, \& Tan, (2013), kecintaan individu pada uang dapat diukur dengan peran etikanya pada uang, baik sebagai hal yang negatif maupun positif. Menurut Ratnasari, Wirajaya, \& Supadmi (2007), pandangan etis pada tax evasion adalah tindakan yang etis untuk dilakukan. Hal ini mengakibatkan perubahan pola pandangan yang bertentangan di masyarakat. Individu dengan love of money yang tinggi akan memprioritaskan uangnya dalam aspek memenuhi kehidupan sehingga menjadi kurang etis, berbeda dengan individu yang memiliki love of money yang rendah. Berdasarkan uraian diatas maka hipotesis Ketiga $\left(\mathrm{H}^{3}\right)$ dalam penelitian ini adalah sebagai berikut:

$\mathrm{H}_{3}$ : Love of money memoderasi hubungan antara money ethic dengan tax evasion

\section{METODE PENELITIAN}

Penelitian ini adalah penelitian kuantitatif. Populasi dalam penelitian ini adalah wajib pajak orang pribadi di Daerah Istimewa Yogyakarta. Sampel dalam penelitian ini adalah wajib pajak orang pribadi yang berada di kabupaten Gunungkidul. Pengambilan sampel dalam penelitian ini menggunakan purposive sampling, dengan kriteria (1) wajib pajak orang pribadi yang memiliki NPWP, (2) wajib pajak orang pribadi yang melakukan kegiatan usaha atau pekerjaan bebas. Pengumpulan data dalam penelitian menggunakan kuesioner yang disebarkan langsung kepada responden yang memenuhi kriteria. Teknik analisis data dalam penelitian ini menggunakan Partial Least Square dengan bantuan WarpPLS. Variabel penelitian ini terdiri dari Money Ethic, Love of Money dan Tax Evasion. Definisi operasional dan pengukuran variabel disajikan pada tabel I. 
Tabel I. Definisi Operasional dan Pengukuran Variabel

\begin{tabular}{|c|c|c|c|c|}
\hline Keterangan & $\begin{array}{c}\text { Definisi } \\
\text { Operasional }\end{array}$ & Referensi & Pengukuran & Referensi \\
\hline Tax Evasion & \begin{tabular}{llr}
\multicolumn{2}{l}{ Penghindaran } & pajak \\
yang dilakukan & oleh \\
wajib pajak & secara \\
ilegal. & &
\end{tabular} & $\begin{array}{l}\text { (Rosianti \& } \\
\text { Mangoting, } \\
\text { 2014) }\end{array}$ & $\begin{array}{l}\text { Enam item } \\
\text { pertanyaan dan } \\
\text { diukur } \\
\text { menggunakan } \\
\text { skala likert lima } \\
\text { poin. }\end{array}$ & $\begin{array}{c}\text { (Mehrad \& } \\
\text { Mohammadi, } \\
\text { 2017) }\end{array}$ \\
\hline Money Ethic & $\begin{array}{l}\text { Perbedaan skala } \\
\text { prioritas tiap individu } \\
\text { dalam menggunakan } \\
\text { uang untuk kebutuhan } \\
\text { sehari-hari }\end{array}$ & $\begin{array}{l}\text { (Hafizhah, } \\
\text { 2016) }\end{array}$ & $\begin{array}{l}\text { Delapan } r \text { Belas } \\
\text { item pertanyaan } \\
\text { dan diukur } \\
\text { menggunakan } \\
\text { skala likert lima } \\
\text { poin. }\end{array}$ & (Azjen, 1977) \\
\hline $\begin{array}{l}\text { Love of } \\
\text { Money }\end{array}$ & 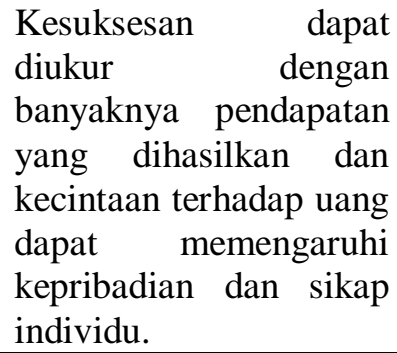 & (Aziz, 2016) & $\begin{array}{lr}\text { Delapan } & \text { item } \\
\text { pertanyaan } & \text { dan } \\
\text { diukur } & \\
\text { menggunakan } & \\
\text { skala likert lima } \\
\text { poin. }\end{array}$ & (Azjen, 1977) \\
\hline
\end{tabular}

Penelitian ini melakukan pilot study terlebih dahulu. Pilot study digunakan untuk mengetahui pernyataan dalam kuesioner sehingga dapat dengan mudah dipahami oleh responden yang akan mengisi. Pilot study dilakukan dengan cara menyebarkan kuesioner kepada responden dalam jumlah kecil. Analisis data dalam penelitian ini menggunakan WarpPLS. WarpPLS sebagai persamaan struktural (SEM) berbasis varian yang secara simultan dapat melakukan pengujian model pengukuran dan pengujian model structural (Nugroho \& Masduqi, 2014).

\section{HASIL DAN PEMBAHASAN}

Respoden dalam penelitian ini berjumlah 42 responden. Respoden dalam penelitian ini didominasi oleh responden berjenis kelamin laki-laki ( 26 responden), dan 16 responden berjenis kelamin perempuan. Usia responden didominasi oleh usia 41-50 tahun yaitu sebanyak 18 responden. Sedangkan tingkat pendidikan terakhir responden didominasi oleh SMA sebanyak 19 responden. Data mengenai usia dan tingkat pendidikan secara rinci disajikan pada tabel 2 .

Tabel 2. Demografi Penelitian

\begin{tabular}{|c|c|}
\hline Keterangan & Frekuensi \\
\hline \multicolumn{2}{|l|}{ Usia } \\
\hline $31-40$ & 17 \\
\hline $41-50$ & 18 \\
\hline$>50$ & 7 \\
\hline \multicolumn{2}{|l|}{ Tingkat Pendidikan } \\
\hline SMP & 13 \\
\hline SMA & 19 \\
\hline Diploma & 2 \\
\hline S1 & 8 \\
\hline
\end{tabular}

Sumber: data primer, diolah (2019).

Penelitian ini melakukan pengujian inner model (model pengukuran) dengan tujuan untuk menguji validitas dan reliabilitas (Tentama, 2019). Uji validitas dalam penelitian ini adalah uji validitas (validitas diskriminan dan validitas konvergen). Menurut Nugroho \& Masduqi (2014), pengujian 
validitas kovergen adalah uji validitas yang terkait dengan pengukuran yang timbul sangat tinggi dari prinsip konstruk. Sedangkan, validitas diskriminan berkaitan dengan konstruk yang seharusnya tidak berkorelasi tinggi atau rendah. Hasil validitas disajikan pada tabel 3.

Tabel 3. Hasil Uji Validitas

\begin{tabular}{|c|c|c|c|c|}
\hline & Tax Evasion & Love of Money & Money Ethic & AVE \\
\hline TE 1 & $(0.735)$ & & & \multirow{6}{*}{$(0.789)$} \\
\hline TE 2 & $(0.833)$ & & & \\
\hline TE 3 & $(0.760)$ & & & \\
\hline TE 4 & $(0.661)$ & & & \\
\hline TE 5 & $(0.788)$ & & & \\
\hline TE 6 & $(0.932)$ & & & \\
\hline LM 1 & & $(0.684)$ & & \multirow{18}{*}{$(0.738)$} \\
\hline LM 2 & & $(0.555)$ & & \\
\hline LM 3 & & $(0.722)$ & & \\
\hline LM 4 & & $(0.602)$ & & \\
\hline LM 5 & & $(0.664)$ & & \\
\hline LM 6 & & $(0.676)$ & & \\
\hline LM 7 & & $(0.768)$ & & \\
\hline LM 8 & & $(0.634)$ & & \\
\hline LM 9 & & $(0.805)$ & & \\
\hline LM 10 & & $(0.785)$ & & \\
\hline LM 11 & & $(0.647)$ & & \\
\hline LM 12 & & $(0.832)$ & & \\
\hline LM 13 & & $(0.840)$ & & \\
\hline LM 14 & & $(0.709)$ & & \\
\hline LM 15 & & $(0.606)$ & & \\
\hline LM 16 & & $(0.790)$ & & \\
\hline LM 17 & & $(0.794)$ & & \\
\hline LM 18 & & $(0.810)$ & & \\
\hline ME 1 & & & $(0.545)$ & \multirow{8}{*}{$(0.733)$} \\
\hline ME 2 & & & $(0.532)$ & \\
\hline ME 3 & & & $(0.663)$ & \\
\hline ME 4 & & & $(0.812)$ & \\
\hline ME 5 & & & $(0.771)$ & \\
\hline ME 6 & & & $(0.767)$ & \\
\hline ME 7 & & & $(0.775)$ & \\
\hline ME 8 & & & $(0.674)$ & \\
\hline
\end{tabular}

Sumber: data perimer, diolah (2019).

Tabel 3 menunjukan bahwa semua item pernyataan kuesioner valid. Hal ini dapat dilihat dari nilai loading yang lebih besar dari 0,5 dan nilai AVE lebih besar dari 0,5 (Imam, G., \& Latan, 2014). Uji reliabilitas bertujuan untuk mengukur konsistensi internal alat ukur. Parameter yang digunakan untuk uji reliabilitas ini yaitu, composite reliability dengan nilai rule of thumb. Hasil Uji Reliabilitas dapat dijelaskan pada tabel 4.

Tabel 4. Hasil Uji Reliabilitas

Nilai Composite Reliability

\begin{tabular}{|c|c|c|}
\hline Tax Evasion & Love of Money & Money Ethic \\
\hline$(0.907)$ & $(0.952)$ & $(0.910)$ \\
\hline
\end{tabular}

Sumber Data diolah (2019).

Tabel 4 menunjukan hasil uji reliabilitas dengan menggunakan metode composite reliability dengan nilai rule of thumb lebih besar dari 0,5. Oleh karena itu, penelitian ini memenuhi uji reliabilitas sehingga data dikatakan valid (Hartono, 2014). 
Tahap selanjutnya yang dilakukan dalam penelitian ini adalah pengujian model struktural. Pengujian struktural dilakukan dengan menggunakan $R$-square dan nilai koefisien path atau $t$-value tiap path. Hasil model struktural disajikan pada gambar 1.

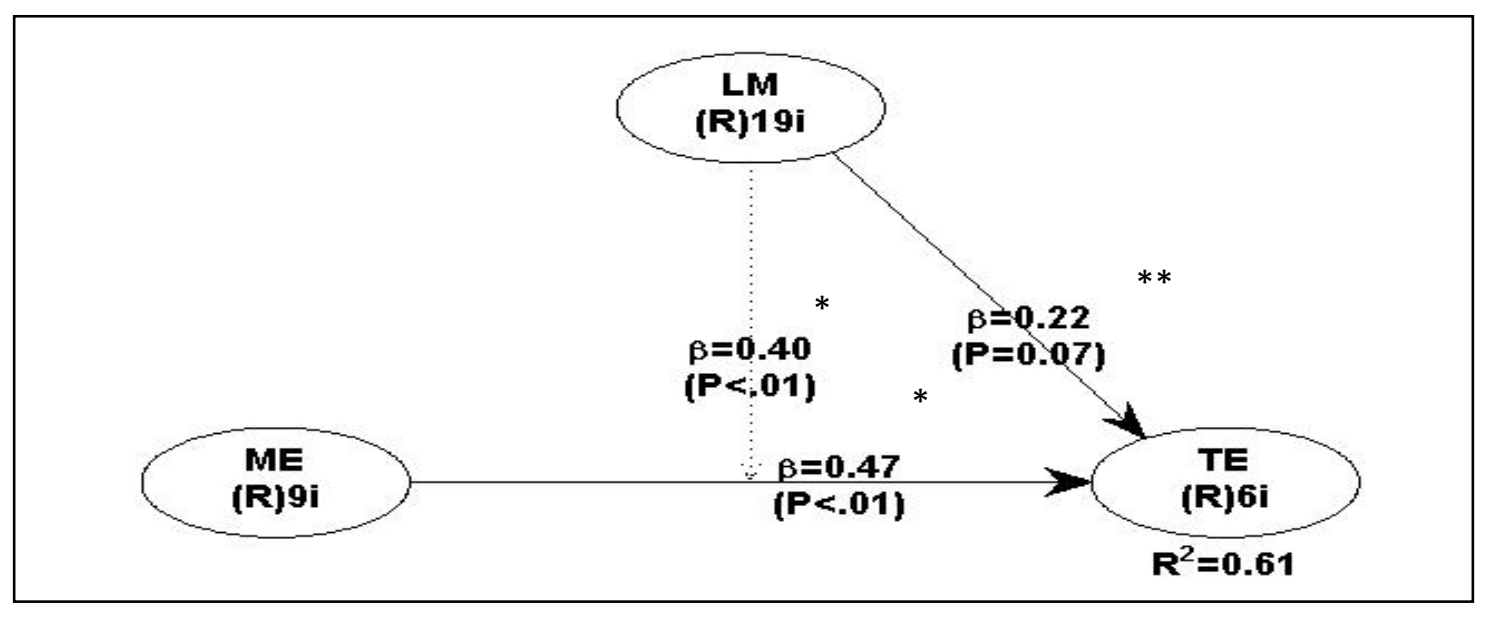

$*$ terdukung $5 \% *$ terdukung $10 \%$

Gambar 1. Hasil Outer Model

Sumber: data primer, diolah (2019).

Gambar 1 menunjukan bahwa tax evasion memiliki nilai $R$-square sebesar 0,61 . Hal ini berarti bahwa variasi perubahan variabel Tax Evasion dapat dijelaskan oleh variabel Money Ethic, dan Love of Money sebesar 61 persen, sedangkan 39 persen dijelaskan oleh variabel lain diluar model penelitian.

Salah satu faktor yang memengaruhi tax evasion dipengaruhi oleh money ethic. Hal ini ditunjukan dengan nilai signifikansi $(<0,01)$ yang lebih kecil dari 0,05 . Dengan kata lain, hipotesis pertama $\left(\mathrm{H}_{1}\right)$ penelitian ini terdukung. Oleh karena itu, Money Ethic berpengaruh terhadap Tax Evasion. Hal ini didukung dari hasil penelitian yang dilakukan oleh Putu, Murtining, \& Dwiyanti (2019), bahwa tinggi maupun rendahnya Money Ethic akan sangat memengaruhi perilaku atau sikap dalam diri seseorang sehingga akan dengan mudah timbul terjadinya kecurangan pajak.

Faktor lain yang dapat memengaruhi tax evasion adalah love of money. Hal ini ditunjukan dengan nilai signifikansi $(0,07)$ yang lebih kecil dari 0,10 . Dengan kata lain, hipotesis kedua $\left(\mathrm{H}_{2}\right)$ penelitian ini terdukung. Oleh karena itu, Love of Money berpengaruh terhadap tax evasion. Menurut penelitian Putu, Murtining, \& Dwiyanti (2019), menyatakan bahwa semakin tinggi tingkat love of money yang dimiliki seseorang wajib pajak maka akan semakin tinggi pula seorang wajib pajak akan melakukan penggelapan pajak (tax evasion), hal tersebut dikarenakan semakin cintanya seseorang terhadap uang.

Hasil uji Moderasi menunjukkan bahwa Love of Money memoderasi antara Money Ethic dan tax xvasion. Hal ini ditunjukan dengan nilai signifikansi $(<0,01)$ yang lebih kecil dari 0,05 . Dengan kata lain, hipotesis ketiga $\left(\mathrm{H}_{3}\right)$ penelitian ini terdukung. Oleh karena itu, ketika individu mencintai uangnya maka terdapat sikap yang timbul sehingga dalam pendangan individu tersebut cenderung mengganggap tax evasion adalah tindakan yang etis untuk dilakukan, sehingga terjadi perubahan pandangan yang mulanya positif menjadi negatif (Ratnasari et al., 2007).

\section{KESIMPULAN}

Penelitian ini memperoleh hasil bahwa penggelapan pajak dipengaruhi oleh money ethic (etika uang) dan love of money (cinta uang). Penelitian ini juga membuktikan bahwa love of money (cinta uang) memoderasi pengaruh antara money ethic (etika uang) dengan penggelapan pajak. Sehingga, individu ketika akan melakukan pembayaran pajak akan merasakan bahwa uang yang dimiliki sangat berharga dan sangat penting dalam kehidupan sehari-hari, hal ini akan menyebabkan timbul sikap individu untuk melakukan penggelapan pajak. Selain itu, love of money (cinta uang) memoderasi tax evasion (penggelapan pajak). Hal ini dapat disimpulkan bahwa peran individu dalam kecintaan terhadap uang akan berpotensi secara langsung maupun tidak langsung terhadap pembayaran pajak. 
Keterbatasan dalam penelitian ini adalah jumlah sampel dalam penelitian ini relatif sedikit. Oleh karena itu, diharapkan penelitian selanjutanya dapat memperluas objek penelitian atau menambah jumlah sampel penelitian.

\section{DAFTAR PUSTAKA}

Aziz, T. I., \& Taman, A. (2016). Pengaruh Love Of Money Dan Machiavellian Terhadap Persepsi Etis Mahasiswa Akuntansi (Studi Empiris Pada Mahasiswa Akuntansi UNY Angkatan 2013 dan Angkatan 2014). Nominal, Barometer Riset Akuntansi Dan Manajemen, 4(2). https://doi.org/10.21831/nominal.v4i2.7998

Azjen, I. F. M. (1977). a Theoretical Analysis and Review of Empirical Research. Psychological Bulletin, 84(5), 888-918.

Basri, Y. M. (Universitas R. (2014). Efek moderasi religuisitas dan gender terhadap hubungan etika uang dan kecurangan pajak. SNA 17 Mataram, Lombok, 1-23.

Basri, Y., \& Silaen, C. (2015). Pengaruh Sistem Perpajakan, Diskriminasi, Teknologi Dan Informasi Perpajakan Terhadap Persepsi Wajib Pajak Mengenai Etika Penggelapan Pajak (Tax Evasion). Jurnal Online Mahasiswa Fakultas Ekonomi Universitas Riau, 2(2), 1-15.

Hafizhah, I. (2016). Pengaruh Etika Uang (Money Ethics) Terhadap Kecurangan Pajak (Tax Evasion) Dengan Religiusitas,Gender dan Materialisme Sebagai Variabel Moderasi. Jurnal Online Mahasiswa (JOM) Bidang Ilmu Ekonomi, 3(1), 1652-1665. Retrieved from https://jom.unri.ac.id/index.php/JOMFEKON/article/view/11770/11418

Hartono, J., \& Abdillah, W. (2014). . Konsep dan Aplikasi (Partial Least Square) untuk Penelitian Empiris (1st ed.). Yogyakarta: BPFE UGM.

Imam, G., \& Latan, H. (2014). (2014). Partial Least Square (PLS) konsep teknik dan aplikasi. Semarang: Universitas Diponegoro Semarang.

Lau, T. C., Choe, K. L., \& Tan, L. P. (2013). (2013). The Moderating Effect of Religiosity in the Relationship between Money Ethics and Tax Evasion. Asian Social Science, 9(11), 213-220.

Mehrad, D., \& Mohammadi, S. (2017). Word of Mouth impact on the adoption of mobile banking in Iran. Telematics and Informatics, 34(7), 1351-1363. https://doi.org/10.1016/j.tele.2016.08.009

Mitchell, T. R., \& Mickel, A. (1999). (n.d.). The Meaning of Money: An Individual Difference Perspective. The Academy of Management Review, 24, 568-578. 1999.

Nugroho, A. R., \& Masduqi, A. (2014). Application of Partial Least Square Structural Equation Modelling for Assessing the Water Pollution Factor of Kali Aplikasi Partial Least Square Structural Equation Modelling Untuk Menilai Faktor Pencemaran Air Application of Partial Least Square Structur. (April 2018).

Putra, D. A. (2019). Penerimaan Pajak Diprediksi Hanya Capai Rp1.348,7 Triliun di 2019. Retrieved from https://www.merdeka.com/uang/penerimaan-pajak-diprediksi-hanya-capai-rp-13487triliun-di-2019.html

Putu, N., Murtining, S., \& Dwiyanti, K. T. (2019). Pengaruh love of money, machiavellian, dan equity sensitivity terhadap persepsi etika penggelapan pajak (Tax Evasion) Fakultas Ekonomi dan Bisnisa UniversitasaPendidikan Nasionalf (Undiknas ), Bali , Indonesia AB. E-Jurnal Akuntansi Universitas Udayana, 26, 1412-1435.

Ratnasari, M. M., Wirajaya, G. A., \& Supadmi, N. L. (2007). Gender Memoderasi Pengaruh Love of Money Terhadap Tax Evasion Tendency. (2006), 197-211.

Rosianti, C., \& Mangoting, Y. (2014). Pengaruh Money Ethics Terhadap Tax Evasion Dengan Intrinsic Dan Extrinsic Religiosity Sebagai Variabel Moderating. Tax \& Accounting Review, 4(1), 1-11.

Siamena, E., Sabijono, H., \& Warongan, J. D. . (2017). Pengaruh Sanksi Perpajakan Dan Kesadaran Wajib Pajak Terhadap Kepatuhan Wajib Pajak Orang Pribadi Di Manado. Going Concern: 
Jurnal Riset Akuntansi, 12(2), 917-927. https://doi.org/10.32400/gc.12.2.18367.2017

Suminarsasi, W. \& S. (2011). Pengaruh Keadilan, Sistem Perpajakan, dan Diskriminasi terhadap Persepsi Wajib Pajak Mengenai Etika Penggelapan Pajak (Tax Evasion).

Tang, T. L. (2002). (n.d.). Is the Love of Money the Root of All Evil? Or Different Strokes for Different Folks : Lessons in 12 Countries. . Paper Presented to the International Conference on Business Ethics in the Knowledge Economy. 2002.

Tentama. (2019). Pengujian Validitas dan Reliabilitas Konstruk pada Organizational Citizenship Behavior. Humanitas, 15(1), 62. https://doi.org/10.26555/humanitas.v15i1.5282

Wankhar, A. Z., \& Diana, N. (2018). Pengaruh Money Ethics Terhadap Tax Evasion Dengan Reliogiousity, Gender, Materialism Sebagai Variabel Moderating (Studi Kasus pada Wajib Pajak Orang Pribadi yang Terdaftar di KPP Pratama Malang Utara). E-Journal Ilmiah Riset Akuntansi Universitas Islam Malang, 7, 44-58. 